\title{
EROSÃO EM ENTRE SULCOS EM ÁREA CULTIVADA COM CANA CRUA E QUEIMADA SOB COLHEITA MANUAL E MECANIZADA ${ }^{(1)}$
}

\author{
Marcos Vinícios Garbiate ${ }^{(2)}$, Antonio Carlos Tadeu Vitorino ${ }^{(3)}$, Bruno \\ Andrade Tomasini ${ }^{(2)}$, Anderson Cristian Bergamin ${ }^{(2)}$ \& Elói Panachuki ${ }^{(4)}$
}

\begin{abstract}
RESUMO
Embora existam vários estudos ligados às questões ambientais voltadas para a poluição atmosférica, ao uso crescente da biotecnologia e à mecanização do processo de colheita da cana-de-açúcar, a mesma atenção não tem sido dada aos impactos ambientais negativos promovidos pela erosão laminar. O presente trabalho teve como objetivo avaliar a concentração de matéria orgânica (MO) e nutrientes ( $\mathrm{P}, \mathrm{K}$, Ca e Mg) em sedimentos e na água da enxurrada proveniente de erosão entre sulcos em diferentes sistemas de manejo na colheita da cana-deaçúcar utilizados no Estado de Mato Grosso do Sul (cana crua e queimada), sob um Latossolo Vermelho distrófico de textura média. Os tratamentos estudados foram colheita manual de cana queimada, colheita mecanizada de cana crua e colheita mecanizada de cana queimada. Aplicou-se chuva simulada com intensidade de $60 \mathrm{~mm} \mathrm{~h}^{-1}$, durante $50 \mathrm{~min}$. As concentrações de sedimentos na enxurrada resultantes da erosão entre sulcos, bem como de MO, P, K, Ca e Mg, foram maiores no sistema com colheita mecanizada de cana queimada e menores no sistema com colheita mecanizada de cana crua. A qualidade física do solo sofre influência negativa do sistema de manejo com colheita mecânica de cana queimada, devido ao efeito da pressão exercida pelo tráfego de máquinas na colheita. No entanto, os resíduos vegetais de colheita distribuídos na superfície do solo pela colheita mecânica de cana crua reduzem as perdas de nutrientes e de MO no sedimento, além de aumentarem a capacidade do solo em resistir à degradação física ocasionada pelo tráfego de máquinas na colheita mecanizada de cana.
\end{abstract}

Termos de indexação: colheita mecanizada, processo erosivo, chuva simulada, cobertura do solo, estabilidade estrutural.

\footnotetext{
(1) Financiado pela Fundação de Apoio ao Desenvolvimento do Ensino Ciência e Tecnologia do Estado de Mato Grosso do Sul (FUNDECT). Recebido para publicação em 4 de abril de 2011 e aprovado em 23 de setembro de 2011.

(2) Aluno do PPG/Agronomia da Universidade Federal da Grande Dourados - UFGD. Rod. MS-270, km 12, Caixa Postal 533, CEP 79804-970 Dourados (MS). E-mail: marcos_garbiate@yahoo.com.br

(3) Professor da Faculdade de Ciências Agrárias, Universidade Federal da Grande Dourados - UFGD. Bolsista de Produtividade CNPq. E-mail: vitorino@ufgd.edu.br

(4) Professor da Universidade Estadual de Mato Grosso do Sul - UEMS. Aquidauana (MS). E-mail: eloip@uems.br
} 


\title{
SUMMARY: INTERRIL EROSION FROM AREA UNDER BURNED AND GREEN SUGARCANE HARVESTED BY HAND AND MECHANICALLY
}

\begin{abstract}
Although a number of studies related to environmental issues address air pollution, the increased use of biotechnology and mechanical harvesting of sugar cane, less attention has been paid to the negative environmental impacts caused by laminar erosion. This study aimed to determine the levels of organic matter $(O M)$ and nutrients $(P, K, C a$ and $M g)$ in sediment and runoff water from interrill erosion from different sugarcane harvest systems (green and burnt cane), on a loamy Dystrophic Red Latosol (Oxisol). The treatments consisted of burnt cane harvested by hand, mechanical harvesting of green cane and mechanical harvesting of burnt cane. A portable rainfall simulator was calibrated to apply rainfall of $60 \mathrm{~mm} \mathrm{~h}^{-1}$, for $50 \mathrm{~min}$. The sediment concentration in runoff resulting from interrill erosion, as well as $O M, P, K, C a$ and $\mathrm{Mg}$ were higher in the system with mechanical harvesting of burnt cane, while losses were lowest from the system with mechanized harvesting of green cane. The soil physical quality is negatively influenced by the management system with mechanical harvesting of burnt cane, due to the pressure exerted by the harvest machine traffic. However, crop residues distributed across the soil surface at mechanical harvesting of green cane reduce losses of soil, nutrients and $O M$ in the sediment, and increase the soil resistance against physical degradation caused by machinery traffic for mechanical harvesting of sugarcane.
\end{abstract}

Index terms: mechanical harvesting, erosion processes, simulated rain, soil cover, structural stability.

\section{INTRODUÇÃO}

O modelo tecnológico atual que trata da produção de cana-de-açúcar, fruto da expansão da cultura em atendimento da demanda de alteração da matriz energética, tem promovido dúvidas sobre sua sustentabilidade. Embora profundamente atentos às questões ambientais voltadas para a poluição atmosférica, ao uso crescente da biotecnologia e à mecanização do processo de colheita, a mesma atenção não tem sido dada aos impactos ambientais negativos promovidos pela erosão laminar.

As técnicas de cultivo utilizadas por agricultores e empresas do setor, que em curto prazo favorecem o desenvolvimento da cultura, podem, com o cultivo contínuo, provocar danos às propriedades do solo (Souza et al., 2005b). A falta de informações precisas sobre as alterações físicas e químicas dos solos submetidos ao cultivo de cana-de-açúcar pode dificultar a identificação dos fatores responsáveis por possíveis quedas de produtividade e, consequentemente, a implantação de práticas de manejo mais adequadas na manutenção das condições agrícolas dos solos. Nesse sentido, Moreti et al. (2003) consideram que o conhecimento das relações entre os fatores que causam as perdas de solo e os que permitem reduzi-las é de fundamental importância na adoção de sistemas de uso conservacionistas. Assim, o sucesso de uma exploração agrícola equilibrada depende, em grande parte, da investigação e do controle dos aspectos referentes aos agentes causadores da erosão, como as chuvas e certos atributos do solo, que, pela ação antrópica, podem favorecer ou dificultar o processo erosivo, já que as atividades humanas constituem os principais agentes catalisadores desses processos (Panachuki et al., 2006).

O tipo de colheita da cana-de-açúcar pode influenciar a produção e longevidade da cultura, os atributos físicos, químicos e biológicos, o meio ambiente e a saúde pública (Souza et al., 2006). O sistema de colheita por cana queimada produz grandes impactos ambientais, como eliminação da biomassa presente na superfície e aumento da concentração de gás carbônico na atmosfera, contribuindo assim com o efeito estufa e com a diminuição da matéria orgânica no solo (Souza et al., 2005a). Além disso, o solo permanece descoberto por um período relativamente longo, o que acelera o processo erosivo e culmina com a degradação da qualidade do solo. Souza et al. (2005a), estudando sistema de manejo e colheita da cana-deaçúcar, observaram que no sistema de manejo de cana crua a adição de resíduos orgânicos foi, em média, de $12 \mathrm{t} \mathrm{ha}^{-1}$. Tim (2002) relata que na colheita de canade-açúcar sem queima dos resíduos culturais ocorre melhoria das condições físicas do solo, como aumento da macroporosidade e da estabilidade dos agregados, redução na resistência à penetração, aumento na permeabilidade, bem como redução da amplitude térmica e manutenção da umidade do solo, o que aumenta o potencial produtivo da cultura.

Cogo et al. (2003) consideram que a cobertura do solo proporcionada pelos resíduos culturais deixados na superfície tem ação direta e efetiva na redução da erosão hídrica, em virtude da dissipação de energia cinética das gotas de chuva, a qual diminui a desagregação do solo e o selamento superficial, além 
de aumentar a infiltração de água, atuando ainda na redução da velocidade do escoamento superficial e, consequentemente, da capacidade erosiva da enxurrada. Panachuki et al. (2006) afirmam que o fator mais importante de alteração da taxa de infiltração de água no solo durante a chuva é a cobertura vegetal que está na superfície do solo. Martins Filho et al. (2009) e Romero (2009) relatam que a cobertura vegetal tem importante papel no controle da erosão e na redução das perdas de matéria orgânica e nutrientes no sedimento em área cultivada com cana-de-açúcar. Prado \& Nóbrega (2005), estudando perdas de solo por erosão laminar em uma bacia hidrográfica com diversas culturas e sistemas de cultivo, associaram importantes perdas de solo em áreas cultivadas com cana-de-açúcar.

Weill \& Sparovek (2008), na busca de indicadores para avaliação do impacto da erosão na qualidade do solo em sistemas de produção agrícola, para serem aplicados como ferramenta de planejamento na interpretação da tolerância de perda de solo em áreas agrícolas, observaram que em mais de 99 \% da área ocupada com cana-de-açúcar as taxas estimadas de perda de solo por erosão superaram a taxa de renovação do solo, caracterizando a degradação desse recurso.

A separação do processo de erosão em entre sulcos e em sulcos pode ajudar a identificar fontes potenciais de sedimentos, o que é extremamente importante na modelagem da distribuição de produtos químicos nas áreas agrícolas, especialmente daqueles que são fortemente adsorvidos pelas partículas do solo (Martins Filho, 2007). A erosão em entre sulcos acontece pela desagregação originada do impacto das gotas de chuva e pelo transporte do escoamento superficial pelo fluxo laminar raso, por arraste e suspensão das partículas superficiais do solo desagregadas, onde se encontram a matéria orgânica e os nutrientes fundamentais para a produção agrícola (Bezerra \& Cantalice, 2006).

A fim de contribuir para o melhor entendimento das questões mencionadas, o presente trabalho teve como objetivo avaliar a concentração de matéria orgânica (MO) e nutrientes (P, K, Ca e Mg) nas fases sólida e líquida do escoamento superficial, proveniente de erosão entre sulcos, e suas relações com alguns atributos físicos do solo, em diferentes sistemas de manejo na colheita da cana-de-açúcar utilizados no Estado de Mato Grosso do Sul (cana crua e queimada), sob um Latossolo Vermelho distrófico de textura média.

\section{MATERIAL E MÉTODOS}

O estudo foi realizado no município de Naviraí - MS, em área da Fazenda Santa Clara localizada nas coordenadas de $23^{\circ} 10^{\prime} 3^{\prime \prime}$ de latitude sul e $54^{\circ} 23^{\prime} 36^{\prime \prime}$ de longitude oeste, em solo classificado como Latossolo Vermelho distrófico textura média (Embrapa, 2006) com declividade de $3 \mathrm{~cm} \mathrm{~m}^{-1}$, cujos resultados de alguns atributos físicos e químicos são apresentados no quadro 1 .

Os testes de campo foram realizados logo após a colheita da cana de terceiro ano, entre os meses de julho e agosto, na safra de 2008. O clima regional, classificado pelo sistema internacional de Köppen, é do tipo Cwa, clima úmido e inverno seco, com precipitação pluvial média anual de $1.500 \mathrm{~mm}$ e temperatura média anual de $22{ }^{\circ} \mathrm{C}$ (Fietz, 2001). A área vem sendo utilizada com a cultura da cana-deaçúcar há mais de 10 anos. O controle de plantas espontâneas é feito regularmente com herbicidas pósemergentes de ação específica sobre as infestantes, e não há registro de utilização de inseticidas e fungicidas nesse período. Na área do experimento não é feita a aplicação de vinhaça. A adubação de plantio forneceu 40,150 e $140 \mathrm{~kg} \mathrm{ha}^{-1}$ de $\mathrm{N}, \mathrm{P}_{2} \mathrm{O}_{5}$ e $\mathrm{K}_{2} \mathrm{O}$, respectivamente, e a adubação de manutenção foi feita com 80 e $100 \mathrm{~kg} \mathrm{ha}^{-1}$ de $\mathrm{N}$ e $\mathrm{K}_{2} \mathrm{O}$, respectivamente.

A colheita mecanizada foi realizada por uma colhedora modelo A7700 com rodado de esteira, sendo a cana recolhida com trator modelo $\mathrm{BH} 180 \mathrm{com}$ peso de embarque lastrado de $7.290 \mathrm{kgf}$, com rodado de 18.426R1 e 24.5-32R1, puxando transbordo com pneus de baixa pressão e alta flutuação.

O delineamento experimental utilizado foi de blocos casualizados com seis repetições. Os tratamentos utilizados foram: colheita manual de cana queimada, colheita mecanizada de cana crua e colheita mecanizada de cana queimada.

Quadro 1. Proporção de argila, silte, areia e argila dispersa em água (ADA) e resultados da análise química, na camada de 0,0 a $20 \mathrm{~cm}$, em um Latossolo Vermelho distrófico sob diferentes sistemas de colheita da cana-de-açúcar

\begin{tabular}{|c|c|c|c|c|c|c|c|c|c|c|c|c|c|c|c|}
\hline \multirow{2}{*}{ Tratamento } & \multicolumn{4}{|c|}{ Fração } & \multicolumn{2}{|c|}{$\mathrm{pH}$} & \multirow{2}{*}{ MO } & \multirow{2}{*}{$\mathbf{P}$} & \multirow{2}{*}{$\mathbf{K}^{+}$} & \multirow{2}{*}{$\mathrm{Ca}^{2+}$} & \multirow{2}{*}{$\mathrm{Mg}^{2+}$} & \multirow{2}{*}{$\mathbf{H}+\mathbf{A l}$} & \multirow{2}{*}{ SB } & \multirow{2}{*}{$\mathbf{T}$} & \multirow{2}{*}{$\mathbf{V}$} \\
\hline & Argila & Silte & Areia & ADA & $\overline{\mathrm{CaCl}_{2}}$ & $\mathrm{H}_{2} \mathrm{O}$ & & & & & & & & & \\
\hline & $\longrightarrow$ & Textu & $a\left(\mathrm{~g} \mathrm{~kg}^{-1}\right)$ & & & & $\mathrm{g} \mathrm{kg}^{-1}$ & $\mathrm{mg} \mathrm{dm} \mathrm{m}^{-3}$ & & & $-\mathrm{cm}$ & $\mathrm{l}_{\mathrm{c}} \mathrm{dm}^{-3}-$ & & & $\%$ \\
\hline Manual Queimada & 155,74 & 27,86 & 816,01 & 32,84 & 4,72 & 5,64 & 13,58 & 4,52 & 0,12 & 1,42 & 0,56 & 1,74 & 2,097 & 3,84 & 54,6 \\
\hline Mecânica Crua & 130,49 & 23,13 & 846,99 & 25,22 & 4,59 & 5,57 & 16,34 & 7,09 & 0,30 & 1,48 & 0,75 & 1,67 & 2,531 & 4,20 & 60,3 \\
\hline Mecânica Queima & 155,62 & 25,60 & 818,78 & 33,26 & 4,68 & 5,78 & 13,23 & 2,13 & 0,28 & 1,52 & 0,57 & 1,52 & 2,365 & 3,88 & 60,9 \\
\hline
\end{tabular}


Os testes de perdas de solo em entre sulcos foram determinados em campo, empregando-se o simulador de chuvas portátil denominado InfiAsper (Alves Sobrinho et al., 2002), o qual foi calibrado para aplicar intensidade de precipitação (Ip) de $60 \mathrm{~mm} \mathrm{~h}^{-1}$, utilizando-se bicos VeeJet 80.150 e pressão de serviço de $32 \mathrm{kPa}$. A área de ação do equipamento, ou área da parcela experimental $\left(0,70 \mathrm{~m}^{2}\right)$, foi contornada por um dispositivo de formato retangular, construído em chapas de aço galvanizado número 16, para permitir a obtenção do volume de água escoado superficialmente. A parcela-teste foi sempre instalada com seu maior comprimento no sentido do declive.

As parcelas receberam um pré-molhamento com antecedência de $24 \mathrm{~h}$, com o objetivo de oferecer condições de umidade mais uniforme entre elas, constituindo-se em um pré-requisito antes da aplicação da chuva simulada para obtenção de escoamento superficial (Cogo et al., 1984). Para isso, aplicou-se uma chuva simulada com intensidade de $60 \mathrm{~mm} \mathrm{~h}^{-1}$ durante tempo suficiente para saturar o solo, sem que houvesse escoamento superficial e, consequentemente, carreamento de solo para a calha coletora.

Em cada parcela experimental, foi determinada a umidade inicial do solo momentos antes da aplicação das chuvas simuladas. Para isso, amostras de solo foram coletadas com auxílio de trado tipo holandês, em três profundidades $(0-5,5-10$ e $10-20 \mathrm{~cm})$, nas quais se determinou a umidade do solo pelo método-padrão de estufa (Quadro 2). Ao analisar os dados de umidade inicial, observa-se que não houve diferença estatística significativa entre eles, fato que pode ser atribuído ao efetivo pré-molhamento das parcelas.

Após um intervalo de 24 h da realização do prémolhamento das parcelas, as avaliações de perdas de solo e de água tiveram início, com a coleta de 10 amostras do volume escoado em cada parcela, em intervalos de 5 min entre cada amostra, conforme descrito em Panachuki et al. (2006). A coleta da primeira amostra teve início quando foi verificado o escoamento inicial de água na calha coletora. Se, depois de decorrido o intervalo de tempo, o recipiente não estivesse completamente cheio, a coleta era interrompida, o frasco vedado e era imediatamente iniciada a coleta da amostra seguinte. Caso contrário, se o recipiente ficasse completamente cheio antes de decorrido o intervalo de tempo, a coleta era interrompida, registrando-se o tempo gasto para o enchimento do frasco. Nesse caso, a amostragem seguinte era feita depois de decorridos 5 min do início da coleta anterior. Esse procedimento era repetido até totalizar as 10 amostras, ou seja, durante $50 \mathrm{~min}$ após o início do escoamento superficial em cada parcela.

Durante o período de operação do simulador, a pressão de serviço era constantemente conferida (32 kPa) e, ao final de cada teste na parcela experimental, fazia-se a verificação da intensidade de precipitação real aplicada pelo simulador. Com o auxílio dos dados de pressão, intensidade de precipitação e altura dos bi$\cos (2,30 \mathrm{~m})$, procedeu-se ao cálculo da energia cinética da chuva simulada, utilizando-se para isso o programa computacional EnerChuva, desenvolvido por Alves Sobrinho et al. (2001).

No final da avaliação de campo, as amostras foram encaminhadas para o laboratório em frascos vedados, até ser efetuada a devida separação da fase líquida da fase sólida contida na amostra de escoamento superficial, utilizando-se o processo de decantação, a fim de serem realizadas as medições da massa de solo e do volume de água escoado. Em seguida, o excesso de água era retirado, e o volume, quantificado e registrado. Nessas amostras de água foram determinados os teores de $\mathrm{Ca}, \mathrm{Mg}, \mathrm{K}$ e $\mathrm{P}$ solúveis, conforme Embrapa (1997), sendo descontados dos valores obtidos os teores médios encontrados na análise da água usada na chuva simulada $(0,11 ; 0,03 ; 0,01$; e $0,01 \mathrm{mg} \mathrm{dm}^{-3}$, respectivamente para $\mathrm{Ca}, \mathrm{Mg}, \mathrm{K}$ e P solúveis).

As amostras de material sólido assim obtidas foram colocadas em estufa, em temperatura de $60{ }^{\circ} \mathrm{C}$, por período de tempo necessário à completa evaporação da água nelas contida. A umidade retida nas amostras foi determinada, e o valor obtido foi acrescido ao volume de água inicialmente registrado. A massa do material sólido foi obtida por pesagem, determinando-se em seguida a densidade de partículas, bem como os valores de carbono orgânico (posteriormente transformado para matéria orgânica), $\mathrm{Ca}^{2+}, \mathrm{Mg}^{2+}, \mathrm{K}^{+}$e $\mathrm{P}$ disponível, conforme Embrapa (1997).

Após os testes de campo, foram retiradas amostras de solo com estrutura preservada nas parcelas experimentais, em três profundidades (0-5, 5-10 e 10$20 \mathrm{~cm}$ ), para análises de densidade do solo, porosidade

Quadro 2. Umidade do solo no momento anterior à aplicação da chuva simulada para obtenção do escoamento superficial

\begin{tabular}{cccc}
\hline \multirow{2}{*}{ Profundidade } & Manual Queimada & Mecânica Crua & Mecânica Queimada \\
\hline \multirow{2}{*}{$\mathrm{cm}$} & & Umidade inicial do solo $\left(\operatorname{dag~kg}^{-1}\right)$ & \\
\cline { 3 - 3 } & & $10,01 \mathrm{a}$ & $9,80 \mathrm{a}$ \\
$5-10$ & $9,93 \mathrm{a}$ & $11,95 \mathrm{a}$ & $10,06 \mathrm{a}$ \\
$10-20$ & $9,72 \mathrm{a}$ & $10,62 \mathrm{a}$ & $9,47 \mathrm{a}$ \\
\hline
\end{tabular}

Médias seguidas de mesma letra na coluna não diferem significativamente pelo teste de Tukey a $5 \%$. 
total, macroporosidade e microporosidade do solo, de acordo com os critérios estabelecidos em Embrapa (1997). Determinou-se, ainda, a distribuição de agregados por peneiramento úmido para amostras coletadas nessas três profundidades. Para isso, utilizaram-se amostras com estrutura preservada, que, após secas ao ar, foram passadas em peneiras de 9,52 e 4,76 $\mathrm{mm}$; foram empregados nas análises posteriores os agregados retidos na peneira de $4,76 \mathrm{~mm}$. A análise de estabilidade de agregados foi realizada procedendo-se ao peneiramento, durante $15 \mathrm{~min}$, em jogo de peneiras com malhas de 2,0;1,0;0,5; e 0,105 mm, dentro do recipiente com água. Adotaram-se como índices de estabilidade o diâmetro médio geométrico e o diâmetro médio ponderado, cujos cálculos foram feitos seguindo-se a proposta de Kemper \& Rosenau (1986).

Para avaliar o efeito dos sistemas de manejo da colheita da cana-de-açúcar e obter uma estimativa da variância residual, foi feita análise de variância dos dados obtidos, com posterior aplicação do teste de Tukey a $5 \%$, para comparação de médias. A análise estatística foi feita utilizando-se o aplicativo computacional SAEG (Ribeiro Júnior, 2001).

\section{RESULTADOS E DISCUSSÃO}

A estabilidade de agregados medida pelo diâmetro médio geométrico (DMG) e diâmetro médio ponderado (DMP) nas camadas de 0-5, 5-10 e 10-20 cm foi alterada pelos sistemas de manejo da colheita de cana (Quadro 3), sendo observada redução no DMG e DMP com a colheita mecanizada de cana queimada, comparada com os sistemas de manejo de colheita manual queimada e mecânica crua. Aumentos na concentração de agregados estáveis em água, em cultivos com colheita de cana crua, foram registrados por Ceddia et al. (1999) e Souza et al. (2005a).
Os valores de diâmetro médio de agregados encontrados neste trabalho estão próximos aos encontrados por Souza et al. (2005a) em Latossolo Vermelho-Amarelo distrófico de textura média sobre cultivos de cana com colheita manual queimada e colheita mecânica crua.

A maior estabilidade de agregados no sistema de colheita mecânica de cana crua deve-se provavelmente ao maior teor de matéria orgânica nele observado (Quadro 1), concordando com os dados de Souza et al. (2005a). A redução na estabilidade de agregados verificada pela redução no DMG e DMP com o sistema de colheita mecanizada de cana queimada pode ser atribuída à provável desagregação mecânica que ocorre por efeito da pressão exercida pelo tráfego de máquinas na colheita. Entretanto, uma forte estabilidade estrutural associada à cobertura com resíduos vegetais de colheita pode minimizar esse problema, como constatado no sistema de colheita mecanizada de cana crua, que apresentou maiores valores de DMG e DMP comparados aos do sistema de colheita mecanizada cana queimada. Shukla et al. (2003) e Lado et al. (2004) verificaram proteção na estabilidade de agregados em solos que apresentam cobertura com resíduos vegetais mantidos na superfície.

Os maiores valores de DMG foram encontrados nas camadas de 5-10 e 10-20 cm, não sendo observada alteração no DMP até $20 \mathrm{~cm}$ de profundidade. Blair (2000) encontrou valores de DMG superiores em $30 \%$ quando utilizou o manejo de cana crua após seis anos de cultivo, em relação à cana queimada, na profundidade de 0-10 cm. Souza et al. (2005a) também observaram, em Latossolo Vermelho-Amarelo distrófico de textura média, maiores valores de DMG na camada de 0-10 cm. Ceddia et al. (1999), em Argissolo Amarelo distrófico de textura arenosa, verificaram em cana queimada menores valores do DMP na superfície, enquanto no tratamento cana crua os diâmetros médios dos agregados foram maiores na superfície e tenderam a diminuir com a profundidade.

Quadro 3. Valores médios de diâmetro médio geométrico (DMG) e diâmetro médio ponderado (DMP) nos sistemas de manejo da colheita de cana e em diferentes profundidades

\begin{tabular}{|c|c|c|c|c|}
\hline Profundidade & Manual Queimada & Mecânica Crua & Mecânica Queimada & Média \\
\hline $\mathrm{cm}$ & \multicolumn{3}{|c|}{ Diâmetro Médio Geométrico (mm) } & \\
\hline $\begin{array}{c}0-5 \\
5-10 \\
10-20\end{array}$ & $\begin{array}{l}1,61 \\
2,01 \\
1,74\end{array}$ & $\begin{array}{l}1,90 \\
2,02 \\
1,95\end{array}$ & $\begin{array}{l}1,05 \\
1,21 \\
1,27\end{array}$ & $\begin{array}{l}1,52 \mathrm{~b} \\
1,75 \mathrm{a} \\
1,66 \mathrm{ab}\end{array}$ \\
\hline Média & $1,78 \mathrm{a}$ & $1,95 \mathrm{a}$ & $1,18 \mathrm{~b}$ & \\
\hline $\begin{array}{c}0-5 \\
5-10 \\
10-20\end{array}$ & $\begin{array}{l}2,27 \\
2,51 \\
2,34\end{array}$ & $\begin{array}{l}\text { etro Médio Pondera } \\
\qquad \begin{array}{c}2,44 \\
2,51 \\
2,47\end{array}\end{array}$ & $\begin{array}{l}1,70 \\
1,92 \\
1,99\end{array}$ & $\begin{array}{l}2,14 \mathrm{a} \\
2,31 \mathrm{a} \\
2,27 \mathrm{a}\end{array}$ \\
\hline Média & $2,37 \mathrm{a}$ & $2,48 \mathrm{a}$ & $1,87 \mathrm{~b}$ & \\
\hline
\end{tabular}

Médias seguidas da mesma letra não diferem significativamente pelo teste de Tukey a $5 \%$. 
Os menores valore de DMG e DMP no sistema de colheita mecanizada de cana queimada são indicadores de que ocorre um processo de destruição dos agregados do solo nesse sistema. Essa desagregação aumenta a densidade do solo (Ds), conforme verificado pela análise dos dados no quadro 4. Esses resultados concordam com os de Ceddia et al. (1999), que analisaram diferentes sistemas de manejo de colheita de cana em Argissolo Amarelo distrófico de textura arenosa.

Os sistemas de manejo alteraram a Ds somente até $10 \mathrm{~cm}$ de profundidade (Quadro 4), tendo-se constatado que em sistema de cultivo de cana com colheita mecanizada o tráfego de máquinas provoca aumento expressivo da compactação nessa profundidade. Secco et al. (2004); Collares et al. (2006) e Freddi et al. (2007), analisando o tráfego de máquinas, também observaram alterações na Ds na camada mais superficial do solo.

Os valores de Ds aumentaram com a profundidade no sistema colheita manual; a Ds foi menor de 0-5 e maior de $10-20 \mathrm{~cm}$. Nos locais onde a colheita foi mecanizada o mesmo não aconteceu. Nesses sistemas, não houve diferença da Ds entre as profundidades na área de colheita mecanizada de cana crua; para colheita mecânica de cana queimada, os valores nas duas primeiras profundidades foram iguais entre si e superiores ao encontrado na de 10-20 cm.

O sistema de colheita mecanizada de cana queimada apresentou valores mais elevados para a Ds, com incremento de $23 \%$ da Ds na camada de 0$5 \mathrm{~cm}$ de profundidade, comparado com o sistema de colheita manual. O sistema de colheita mecanizada de cana crua obteve valores intermediários para Ds. Observa-se que na camada de $0-10 \mathrm{~cm}$ de profundidade, no sistema de colheita mecanizada de cana crua, a Ds foi menor que no sistema com colheita mecanizada de cana queimada, evidenciando que o solo com cobertura de resíduos vegetais de colheita pode minimizar o efeito do tráfego de colhedoras de cana, pois ele suporta maiores pressões, em comparação com aqueles que não apresentam resíduos vegetais de colheita, o que está de acordo com Shukla et al. (2003) e Lado et al. (2004). Braida et al. (2006) concluíram que o valor da densidade de solo decresce com a quantidade de palha que permanece na superfície do solo.

Luca et al. (2008) observaram compactações significativas na camada de $0-10 \mathrm{~cm}$ em solos arenosos (PVAd e RQo) sob o manejo sem queima e colheita mecanizada, comparado com a queima manual. Souza et al. (2005a), em Latossolo Vermelho-Amarelo distrófico de textura média, observaram maior Ds quando o sistema utilizado foi a colheita mecanizada da cana sem queima, em relação à colheita manual com queima.

A compactação traz consequências negativas à porosidade do solo, com redução da porosidade total $(\mathrm{Pt})$ e da macroporosidade, fato não observado para a microporosidade do solo (Quadro 4). Os resultados seguem a mesma tendência dos obtidos por Streck et al. (2004) em Argissolo Vermelho-Amarelo distrófico cultivado em sistema de plantio direto, quando trafegado por máquina.

A Pt nas profundidades de 5-10 e 10-20 cm reduziu apenas no sistema de colheita manual queimada, onde o sistema apresentou os menores valores para esse atributo (Quadro 4). Observa-se ainda que os maiores valores de $\mathrm{Pt}$ foram encontrados na área onde a colheita foi realizada de maneira manual. O sistema de colheita mecanizada de cana crua obteve valores intermediários para $\mathrm{Pt}$.

Quadro 4. Valores médios de macroporosidade, microporosidade, porosidade total e densidade do solo nos sistemas de manejo da colheita de cana e em diferentes profundidades

\begin{tabular}{|c|c|c|c|c|}
\hline Profundidade & Manual Queimada & Mecânica Crua & Mecânica Queimada & Média \\
\hline $\mathrm{cm}$ & \multicolumn{3}{|c|}{ Macroporosidade (\%) } & \\
\hline $0-5$ & 26,11 & 15,36 & 17,46 & 19,64 \\
\hline $5-10$ & 26,70 & 18,86 & 12,04 & 19,20 \\
\hline $10-20$ & 23,54 & 16,87 & 13,28 & 17,90 \\
\hline \multirow[t]{2}{*}{ Média } & $25,45 \mathrm{~A}$ & $17,03 \mathrm{~B}$ & $14,26 \mathrm{~B}$ & \\
\hline & \multicolumn{3}{|c|}{ Microporosidade (\%) } & \\
\hline $0-5$ & 22,51 & 24,44 & 22,78 & 23,24 \\
\hline $5-10$ & 24,47 & 24,79 & 24,32 & 24,53 \\
\hline $10-20$ & 26,72 & 24,99 & 24,16 & 25,29 \\
\hline \multirow[t]{2}{*}{ Média } & $24,57 \mathrm{~A}$ & $24,74 \mathrm{~A}$ & $23,75 \mathrm{~A}$ & \\
\hline & \multicolumn{3}{|c|}{ Porosidade Total (\%) } & \\
\hline $0-5$ & $48,62 \mathrm{Aa}$ & $39,80 \mathrm{Ba}$ & $40,24 \mathrm{Ba}$ & \\
\hline $5-10$ & $51,17 \mathrm{Aa}$ & $43,65 \mathrm{Ba}$ & $36,36 \mathrm{Cb}$ & \\
\hline \multirow[t]{2}{*}{$10-20$} & $50,26 \mathrm{Aa}$ & $41,85 \mathrm{Ba}$ & $37,44 \mathrm{Cb}$ & \\
\hline & \multicolumn{3}{|c|}{ Densidade do solo $\left(\mathrm{g} \mathrm{dm}^{-3}\right)$} & \\
\hline $0-5$ & $1,49 \mathrm{Cb}$ & $1,71 \mathrm{Ba}$ & $1,83 \mathrm{Aa}$ & \\
\hline $5-10$ & $1,56 \mathrm{Cab}$ & $1,67 \mathrm{Ba}$ & $1,84 \mathrm{Aa}$ & \\
\hline $10-20$ & $1,60 \mathrm{Aa}$ & $1,68 \mathrm{Aa}$ & $1,68 \mathrm{Ab}$ & \\
\hline
\end{tabular}

Médias seguidas de mesma letra, minúscula na coluna e maiúscula na linha, não diferem significativamente pelo teste de Tukey a $5 \%$. 
Não houve diferença estatística significativa para os valores de microporosidade. Quanto à macroporosidade, não houve diferenças entre as profundidades; no entanto, entre os sistemas de colheita, verifica-se que a colheita mecânica de cana, independentemente se queimada ou crua, promoveu diminuição dos valores de macroporosidade do solo. Esse fato é reflexo do aumento da densidade do solo promovida pela colheita mecanizada. Souza et al. (2005a), em Latossolo Vermelho-Amarelo distrófico de textura média sobre cultivos de cana com colheita manual queimada e mecânica crua, encontraram redução na macroporosidade do solo até $20 \mathrm{~cm}$ de profundidade, onde se utilizou máquina na colheita de cana; esse efeito é justificando pela maior densidade do solo, que se refletiu em menor macroporosidade no sistema de colheita de cana crua, comparada à colheita manual de cana queimada.

$\mathrm{Na}$ figura 1 são apresentadas as equações de regressão com os respectivos coeficientes de determinação, para as perdas de solo em entre sulcos nos diferentes sistemas de colheita da cana. Nota-se que essas perdas foram maiores no sistema com colheita mecanizada de cana queimada e menores naquele com colheita mecanizada de cana crua. Essa diferença pode ser atribuída à cobertura do solo com resíduos vegetais de colheita, tendo sido estimado um aporte de $10.500 \mathrm{~kg} \mathrm{ha}^{-1}$ de resíduos no sistema de colheita mecanizada de cana crua. Por outro lado, os sistemas de colheita com queima do canavial deixam a superfície totalmente exposta à ação do impacto das gotas de chuva, o que ocasiona selamento superficial, reduz a infiltração de água e aumenta o transporte das partículas do solo, como relatado por Albuquerque et al. (2001, 2002), Mello et al. (2003), Martins Filho et al. (2009) e Romero (2009). É importante lembrar que a rugosidade proporcionada pelos resíduos sobre a superfície dos solos contribui para a redução do escorrimento superficial, conforme trabalho realizado

-Queimada manual @ Crua mecanizada $\triangle$ Queimada mecanizada

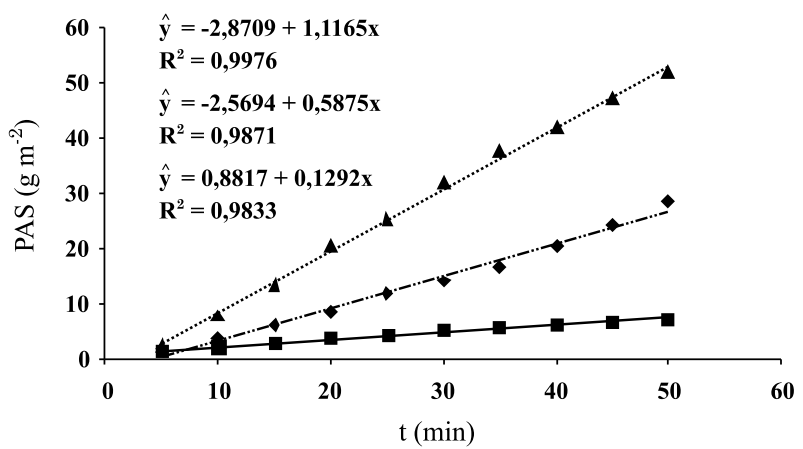

Figura 1. Perda acumulada de solo - PAS em função do tempo - $t$ de aplicação da chuva simulada nos sistemas de cana com colheita manual (queimada) e mecanizada (crua e mecanizada). por Panachuki et al. (2010) com chuva simulada. Assim, a biomassa, mesmo sem alterar a rugosidade da superfície do solo, promove barreiras que reduzem a velocidade do escoamento superficial, dando mais tempo para a água infiltrar.

Com a cobertura do solo proporcionada pelos resíduos vegetais de colheita mecanizada de cana crua, houve preservação do estado de agregação do solo, em razão do menor impacto das gotas de chuva na superfície do solo, diminuindo assim a destruição de agregados da camada superficial do solo, o que concorda com os resultados de Martins Filho et al. (2009), que trabalharam em um Argissolo VermelhoAmarelo eutrófico de textura média, com chuvas simuladas com intensidade média de $60 \mathrm{~mm} \mathrm{~h}^{-1}$, durante $65 \mathrm{~min}$.

Resultados semelhantes foram observados por Cassol et al. (2004), Bezerra \& Cantalice (2006) e Cantalice et al. (2009), que, com o aumento na percentagem de cobertura do solo, obtiveram taxas de desagregação decrescentes. Bezerra \& Cantalice (2006) recomendam a cobertura do solo como prática conservacionista para controle da erosão. Para Cogo et al. (2003), a capacidade erosiva das enxurradas é aumentada quando o solo apresenta baixa cobertura superficial. Além disso, os resíduos vegetais na superfície do solo reduzem a velocidade do escoamento superficial e aumentam a resistência e a altura mínima da lâmina para que ocorra escoamento (Cassol et al., 2004). Estudando a erosão entre sulcos sob chuva simulada, Cantalice et al. (2009) relatam que os resíduos deixados na superfície do solo reduzem as taxas de desagregação do solo e aumentam a resistência ao escoamento superficial.

Observa-se tendência de aumento linear da quantidade de sedimentos encontrados na enxurrada com o tempo, bem como no volume desta com o tempo de precipitação (Figura 1). Mermut et al. (1997) também observaram esse mesmo tipo de tendência. Para Amorin et al. (2001), essa linearidade da perda acumulada de solo em função do tempo indica que, na modelagem do processo erosivo, pode-se considerar uma taxa de perda de solo constante ao longo do tempo.

As concentrações de sedimentos na enxurrada foram maiores nos sistemas com colheita mecanizada de cana (queimada e crua) e menores no sistema com colheita manual de cana queimada (Figura 1). Os maiores volumes de água da enxurrada entre sulcos ocorreram, provavelmente, pelo fato de o solo apresentar limitada capacidade de infiltração, a partir da qual a taxa de escoamento superficial tende a aumentar no solo onde se utiliza a colheita mecânica da cana, devido ao intenso tráfego de máquinas com elevada carga. Souza et al. (2005a) afirmam que a colheita mecânica de cana pode causar compactação do solo. A compactação pode trazer consequências negativas à porosidade, prejudicando a infiltração de água no solo (Ceddia et al., 1999). 
O sistema de colheita mecanizada de cana queimada apresentou as maiores concentrações de $\mathrm{K}$, $\mathrm{Ca}, \mathrm{Mg}$ e MO no sedimento encontrado na enxurrada, enquanto o sistema de colheita mecânica de cana crua apresentou as menores concentrações. As maiores concentrações de nutrientes nos sedimentos oriundos dos sistemas com queima da cana anteriormente à colheita justificam-se pela rápida mineralização do material vegetal ocasionada pela queima, sendo este depositado na superfície do solo (Quadro 5).

Os resultados apresentados no quadro 5 condizem com os obtidos por Cassol et al. (2002). Pode-se observar que os maiores valores de MO, P, K, Ca e Mg ocorreram no sistema com colheita mecanizada de cana queimada, os quais também apresentaram as maiores concentrações de sedimento originado da erosão em entre sulcos (0,53 $\left.\mathrm{t} \mathrm{ha}^{-1}\right)$, ao passo que no sistema com colheita mecanizada de cana crua foram observadas as menores quantidades de perda de solo em entre sulcos (0,07 t ha $\left.{ }^{-1}\right)$ e de P, K, Mg, Ca e MO.

O sistema com colheita manual de cana queimada apresentou valores intermediários $\left(0,27 \mathrm{t} \mathrm{ha}^{-1}\right)$, de nutrientes e MO, quando comparadas aos dos demais sistemas de colheita. Izidorio et al. (2005) avaliaram as perdas de nutrientes no sedimento erodido em área de cana-de-açúcar sem cobertura vegetal no período pós-colheita, aplicando chuva artificial de $80 \mathrm{~mm} \mathrm{~h}^{-1}$, com duração de $65 \mathrm{~min}$, em Latossolo Vermelho eutroférrico de textura muito argilosa, com $8 \mathrm{~cm} \mathrm{~m}^{-1}$ de declividade. Esses autores verificaram que a erosão entre sulcos ocasionou perdas de MO, P, K, Ca e Mg de 19,$75 ; 0,08 ; 0,18 ; 0,67 ;$ e $0,12 \mathrm{~kg} \mathrm{ha}^{-1}$, respectivamente. Hernani et al. (1999) obtiveram, em LatossoloVermelho aluminoférrico epieutrófico, no sistema convencional, em macroparcelas sem cobertura vegetal, valores de perdas de nutrientes de $0,06 \mathrm{~kg} \mathrm{ha}^{-1}$ de $\mathrm{P}, 0,29 \mathrm{~kg} \mathrm{ha}^{-1}$ de $\mathrm{K}, 2,2 \mathrm{~kg} \mathrm{ha}^{-1} \mathrm{de}$ Ca e $0,19 \mathrm{~kg} \mathrm{ha}^{-1}$ de $\mathrm{Mg}$.

Observa-se (Quadro 5) que a perda acumulada de nutrientes e MO nos sedimentos no escoamento superficial em entre sulcos é dependente da quantidade total de sedimentos transportados, além da concentração dos nutrientes e MO nestes, concordando com os dados obtidos por Schick et al. (2000) e Izidorio et al. (2005).
$\mathrm{Na}$ figura 2 são apresentadas as equações de regressão com os respectivos coeficientes de determinação para as perdas acumuladas de água em entre sulcos nos diferentes sistemas de colheita da cana. Nota-se que essas perdas foram maiores nos sistemas com colheita mecanizada e menores no sistema com colheita manual. O sistema de colheita mecanizada, independente da queima ou manutenção da palhada, promoveu compactação do solo, refletida pela diminuição da macroporosidade e da porosidade total do solo, e aumento da sua densidade (Quadro 4). Embora o aumento da quantidade de palha na superfície contribua para a diminuição da densidade do solo (Braida et al., 2006), esse efeito não foi suficiente para diferenciar os valores de perdas acumuladas de água (Figura 2) entre os sistemas com colheita mecanizada.

Bezerra \& Cantalice (2006) e Cantalice et al. (2009) comentam que a cobertura do solo pode ser uma boa prática conservacionista para controle da erosão. Amorim (2003) observou que a presença de cobertura vegetal associada ao preparo em nível proporcionou redução na perda de água em 87 \%, quando comparada à parcela-padrão. Efeitos negativos da compactação provocada por tráfego de máquinas também foram apontados por Streck et al. (2004).

$\mathrm{Na}$ figura 3 são apresentadas as equações de regressão com os respectivos coeficientes de determinação, para as concentrações de nutrientes na fase líquida

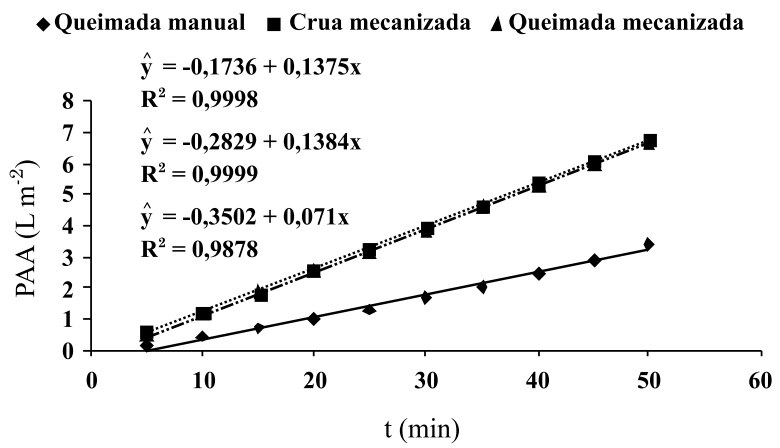

Figura 2. Perda acumulada de água - PAA, em função do tempo - $t$ de aplicação da chuva simulada nos sistemas de cana com colheita manual (queimada) e mecanizada (crua e mecanizada).

Quadro 5. Matéria orgânica (MO) e nutrientes no sedimento da erosão entre sulcos dos sistemas de cana com colheita manual e queimada; mecanizada crua e mecanizada queimada, decorrentes de precipitação de $60 \mathrm{~mm} \mathrm{~h}^{-1}$, com duração de $50 \mathrm{~min}$

\begin{tabular}{|c|c|c|c|c|c|c|}
\hline Sistema de manejo & Sedimento & $\mathbf{P}$ & $\mathbf{K}^{+}$ & $\mathbf{C a}^{2+}$ & $\mathrm{Mg}^{2+}$ & MO \\
\hline & $\mathrm{tha}^{-1}$ & & & $\mathrm{~g} \mathrm{ha}^{-1}$ & & \\
\hline Manual Queimada & 0,27 & $3,5 \mathrm{a}$ & $25,2 \mathrm{~b}$ & $37,0 \mathrm{a}$ & $10,4 \mathrm{a}$ & $4664,2 \mathrm{~b}$ \\
\hline Mecânica Crua & 0,07 & $0,9 \mathrm{a}$ & $4,9 \mathrm{~b}$ & $14,7 \mathrm{~b}$ & $5,2 \mathrm{~b}$ & $1071,9 \mathrm{~b}$ \\
\hline Mecânica Queimada & 0,53 & $5,0 \mathrm{a}$ & $95,2 \mathrm{a}$ & $109,1 \mathrm{a}$ & $44,4 \mathrm{a}$ & 10379,0 a \\
\hline
\end{tabular}



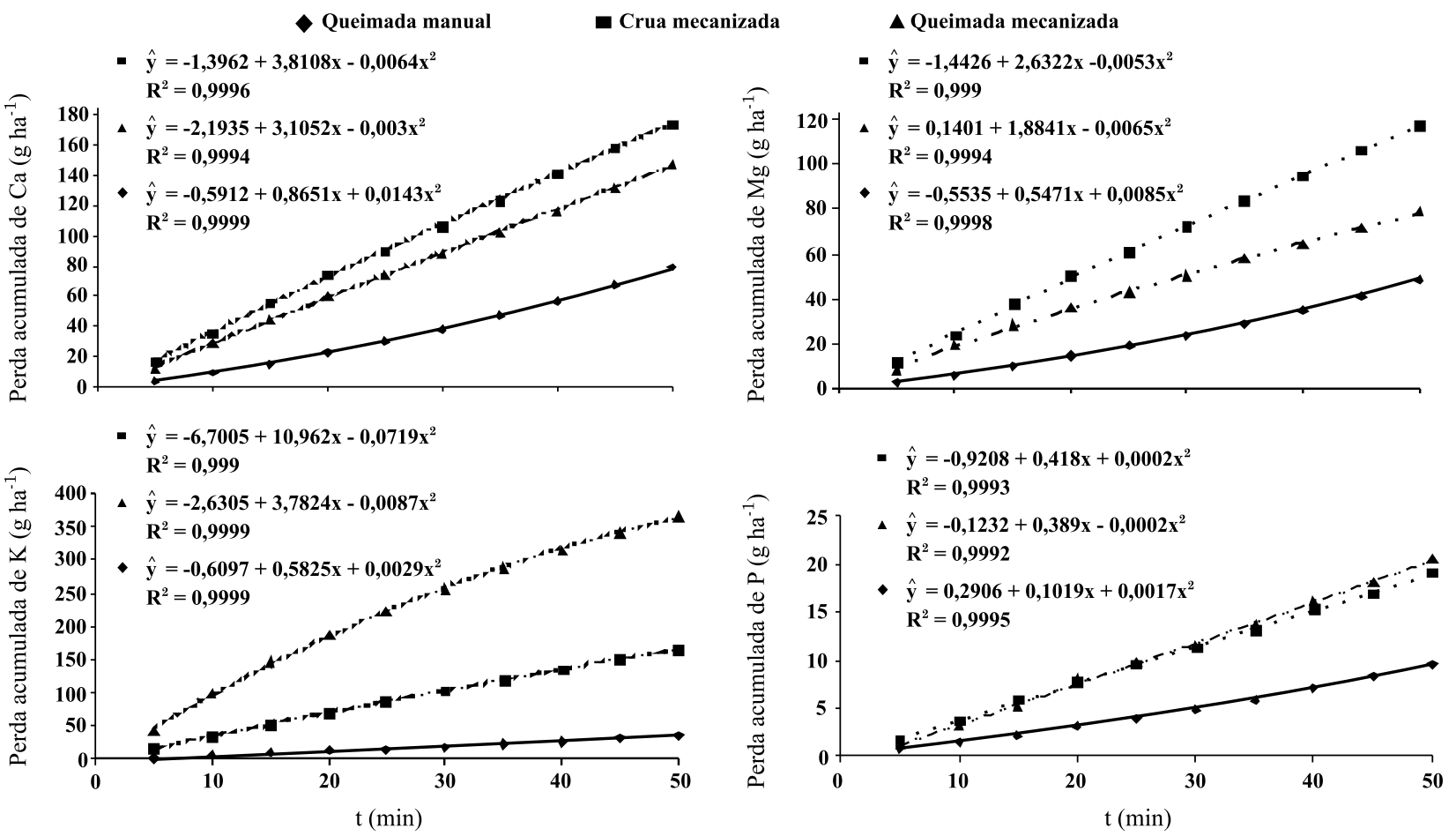

Figura 3. Perda acumulada de $\mathrm{Ca}, \mathrm{Mg}, \mathrm{K}$ e $\mathrm{P}$ na água da enxurrada em função do tempo de aplicação da chuva simulada nos sistemas de cana com colheita manual e queimada; mecanizada crua e mecanizada queimada.

do escoamento superficial em entre sulcos, nos diferentes sistemas de colheita da cana. Nota-se que as concentrações de nutrientes foram maiores nos sistemas com colheita mecanizada de cana (queimada e crua), enquanto as menores ocorreram no sistema com colheita manual de cana queimada.

As concentrações de Ca na água de enxurrada, nos sistemas com colheita mecânica de cana crua, colheita mecânica de cana queimada e colheita manual de cana queimada foram de 173,1, 145,6 e 78,4 $\mathrm{g} \mathrm{ha}^{-1}$, respectivamente. As concentrações de $\mathrm{Mg}$ na água de enxurrada nos sistemas com colheita mecânica de cana crua, colheita mecânica de cana queimada e colheita manual de cana queimada foram de 116,9, 78,0 e 48,1 $\mathrm{g} \mathrm{ha}^{-1}$, respectivamente. Para o Ca e o $\mathrm{Mg}$, observa-se que as maiores concentrações na água de enxurrada ocorreram no sistema com colheita mecanizada de cana crua. Já o $\mathrm{K}$ apresentou maior concentração acumulada na água de enxurrada no sistema com colheita mecanizada de cana queimada, e o P, no sistema de colheita manual de cana queimada.

As perdas de água da chuva pelo escorrimento superficial geralmente são menos influenciadas pelo efeito da cobertura e manejo do solo do que as perdas de solo, já que este apresenta capacidade-limite de absorção de água (Mello et al., 2003; Bertol et al., 2007). Esse processo ocorre especialmente sob chuvas de longa duração e volume elevado, as quais saturam o solo e produzem grandes enxurradas (Bertol et al., 2007).
Portanto, o sistema de colheita mecanizada da cana-de-açúcar, que permite a manutenção da palhada sobre a superfície do solo, reduz as perdas de MO e de nutrientes no sedimento erodido. Contudo, as perdas de nutrientes com a água da enxurrada são maiores em sistemas que mantêm a palhada na superfície do solo, como no sistema de colheita mecanizada de cana crua. Thompson et al. (2001) afirmam que as perdas de nutrientes com a água da enxurrada podem ser elevadas em sistemas conservacionistas, salientando que isso poderá ser um problema para a qualidade das águas superficiais.

\section{CONCLUSÕES}

1. As concentrações de nutrientes no sedimento presente na enxurrada da erosão em entre sulcos seguem a ordem $\mathrm{Ca}>\mathrm{K}>\mathrm{Mg}>\mathrm{P}$ nos sistemas com colheita de cana queimada (mecânica e manual), enquanto no sistema com colheita mecânica de cana crua essa ordem é alterada para $\mathrm{Ca}>\mathrm{Mg}>\mathrm{K}>\mathrm{P}$, acompanhando a ordem relativa dos teores trocáveis do solo.

2. Os resíduos vegetais de colheita distribuídos na superfície do solo pela colheita mecânica de cana crua reduzem as concentrações de sedimentos na enxurrada em entre sulcos em 7,6 vezes e a de MO em 9,7 vezes, comparada com a colheita mecânica de cana queimada, 
enquanto o volume de água escorrida superficialmente praticamente não é influenciado pela cobertura do solo.

3. A qualidade física do solo sofre influência negativa do sistema de manejo com colheita mecânica de cana queimada, devido ao efeito da pressão exercida pelo tráfego de máquinas na colheita. Entretanto, a cobertura com resíduos vegetais oriundos da colheita mecânica de cana crua reduz esses efeitos.

\section{LITERATURA CITADA}

ALBUQUERQUE, A.W.; LOMBARDI NETO, F. \& SRINIVASAN, V.S. Efeito do desmatamento da caatinga sobre as perdas de solo e água de um Luvissolo em Sumé (PB). R. Bras. Ci. Solo, 25:121-128, 2001.

ALBUQUERQUE, A.W.; LOMBARDI NETO, F.; SRINIVASAN, V.S. \& SANTOS, J.R. Manejo da cobertura do solo e de práticas conservacionistas nas perdas de solo e água em Sumé, PB. R. Bras. Eng. Agríc. Amb., 6:136-141, 2002.

ALVES SOBRINHO, T.; CARVALHO, D.F.; AQUINO, R.M. \& MONTEBELLER, C.A. Programa computacional para a definição de parâmetros hidráulicos utilizados na determinação da energia cinética da chuva simulada em infiltrômetro de aspersão. Eng. Rural, 12:28-35, 2001.

ALVES SOBRINHO, T.; FERREIRA, P.A. \& PRUSKI, F.F. Desenvolvimento de um infiltrômetro de aspersão portátil. R. Bras. Eng. Agríc. Amb., 6:337-344, 2002.

AMORIM, R.S.S. Avaliação dos modelos de predição da erosão hídrica USLE, RUSLE e WEPP para condições edafoclimáticas Brasileiras. Viçosa, MG, Universidade federal de Viçosa, 2003. 116p. (Tese de Doutorado)

AMORIN, R.S.S.; SILVA, D.D.; PRUSKI, F.F. \& MATOS, A.T Influência da declividade do solo e da energia cinética de chuvas simuladas no processo de erosão entre sulcos. R. Bras. Eng. Agríc. Amb., 5:124-130, 2001.

BERTOL, I.; ENGEL, F.L.; MAFRA, A.L.; BERTOL, O.J. \& RITTER, S.R. Phosphorus, potassium and organic 15 carbon concentrations in runoff under different soil tillage systems during soybean growth. Soil Tillage Res., 94:142$150,2007$.

BEZERRA, S.A. \& CANTALICE, J.R.B. Erosão entre sulcos em diferentes condições de cobertura do solo, sob cultivo da cana-de-açucar. R. Bras. Ci. Solo, 30:565-573, 2006.

BLAIR, N. Impact of cultivation and sugar-cane green trash management on carbon fractions and aggregate stability for a Chromic Luvisol in Queensland, Australia. Soil Tillage Res., 55:183-191, 2000.

BRAIDA, J.A.; REICHERT, J.M.; VEIGA, M. \& REINERT, D.J. Resíduos vegetais na superfície e carbono orgânico do solo e suas relações com a densidade máxima obtida no ensaio Proctor. R. Bras. Ci. Solo, 30:605-614, 2006.

CANTALICE, J.R.B.; BEZERRA, S.A.; OLIVEIRA, O.F.L. \& MELO, R.O. Hidráulica e taxas de erosão em entre sulcos sob diferentes declividades e doses de cobertura morta. Caatinga, 22:68-74, 2009.
CASSOL, E.A.; LEVIEN, R.; ANGHINONI, I. \& BADELUCCI, M.P. Perdas de nutrientes por erosão em diferentes métodos de melhoramento de pastagem nativa no Rio Grande do Sul. R. Bras. Ci. Solo, 26:705-712, 2002.

CASSOL, E.A.; CANTALICE, J.R.B.; REICHERT, J.M. \& MONDARDO, A. Escoamento superficial e desagregação do solo em entre sulcos em solo franco-argilo-arenoso com resíduos vegetais. Pesq. Agropec. Bras., 39:685-690, 2004 .

CEDDIA, M.B.; ANJOS, L.H.C.; LIMA, E.; RAVELLI NETO, A. \& SILVA, L.A. Sistemas de colheita da cana-de-açúcar e alterações nas propriedades físicas de um solo Podzólico Amarelo no Estado do Espírito Santo. Pesq. Agropec. Bras., 34:1467-1473, 1999.

COGO, N.P.; MOLDENHAUER, W.C. \& FOSTER, G.R. Soil loss reductions from conservation tillage practices as expressed by a mulch factor. Soil Sci. Soc. Am. J., 48:368373, 1984

COGO, N.P.; LEVIEN, R. \& SCHWARZ, R.A. Perdas de solo e água por erosão hídrica influenciadas por métodos de preparo, classes de declive e níveis de fertilidade do solo. R. Bras. Ci. Solo, 27:743-753, 2003.

COLLARES, G.L.; REINERT, D.J.; REICHERT, J.M. \& KAISER, D.R. Qualidade física do solo na produtividade da cultura do feijoeiro num Argissolo. Pesq. Agropec. Bras., 41:1663-1674, 2006.

EMPRESA BRASILEIRA DE PESQUISA AGROPECUÁRIA EMBRAPA. Serviço Nacional de Levantamento e Conservação de Solo. Manual de métodos de análise de solo. Rio de Janeiro, Ministério da Agricultura, 1997. 212p.

EMPRESA BRASILEIRA DE PESQUISA AGROPECUÁRIA EMBRAPA. Centro Nacional de Pesquisa de Solos. Sistema brasileiro de classificação de solos. 2.ed. Rio de Janeiro, 2006. 306p.

FIETZ, C.R. Caracaterização climática da reigião de Dourados visando à prática da irrigação. In: URCHEI, M.A. \& FIETZ, C.R. Princípios de agricultura irrigada: Caracaterizção e potencialidades em Mato Grosso do Sul. Dourados, Embrapa Agropecuária Oeste, 2001. p.69-76. (Documentos, 37)

FREDDI, O.S.; CENTURION, J.F.; BEUTLER, A.N.; ARATANI, R.G. \& LEONEL, C.L. Compactação do solo no crescimento radicular e produtividade da cultura do milho. R. Bras. Ci. Solo, 31:627-636, 2007.

HERNANI, L.C.; KURIHARA, C.H. \& SILVA, W.M. Sistema de manejo de solos e perdas de nutrientes e matéria orgânica por erosão. R. Bras. Ci. Solo, 23:145-54, 1999.

IZIDORIO, R.; MARTINS FILHO, M.V.; MARQUES JÚNIOR, J.; SOUZA, Z.M. \& PEREIRA, G.T. Perdas de nutrientes por erosão e sua distribuição espacial em área sob canade-açúcar. Eng. Agríc., 25:660-670, 2005.

KEMPER, W.D. \& ROSENAU, R.C. Aggregate stability and size distribution. In: KLUTE, A., ed. Methods of soil analysis. Madison, American Society of Agronomy, 1986. v.1. p.425-442. 
LADO, M.; PAZ, A. \& BEM-HUR, M. Organic matter and aggregate size interactions in infiltration, seal formation, and soil loss. Soil Sci. Soc. Am. J., 68:935-942, 2004

LUCA, E.F.; FELLER, C.; CERRI, C.C.; BARTHES, B.; CHAPLOT, V.; CAMPOS, D.C. \& MANECHINI, C. Avaliação de atributos físicos e estoques de carbono e nitrogênio em solos com queima e sem queima de canavial. R. Bras. Ci. Solo, 32:789-800, 2008

MARTINS FILHO, M.V. Modelagem do processo de erosão e padrão espacial da erodibilidade em entre sulcos. Jaboticabal, Universidade Estadual Paulista, 2007. 121p. (Tese de Livre-Docência)

MARTINS FILHO, M.V.; LICCIOTI, T.T.; PEREIRA, G.T.; MARQUES JÚNIOR, J. \& SANCHEZ, R.B. Perdas de solo e nutrientes por erosão num Argissolo com resíduos vegetais de cana-de-açúcar. Eng. Agríc., 29:8-18, 2009.

MELLO, E.L.; BERTOL, I.; ZAPAROLLI, A,L.V. \& CARRAFA, M.R. Perdas de solo e água em diferentes sistemas de manejo de um Nitossolo Háplico submetido à chuva simulada. R. Bras. Ci. Solo, 27:901-909, 2003.

MERMUT, A.R.; LUCK, S.H.; ROMKENS, M.J.M. \& POESEN, J.W.A. Soil loss by splash and wash during rainfall from two loess soils. Geoderma, 75:203-214, 1997.

MORETI, D.; CARVALHO, M.P.; MANNIGEL, A.R. \& MEDEIROS, L.R. Importantes características de chuva para a conservação do solo e da água no município de São Manuel (SP). R. Bras. Ci. Solo, 1:713-726, 2003.

PRADO, J.P.B. \& NÓBREGA, M.T. Determinação de perdas de solo na bacia hidrográfica do Córrego Ipiranga em Cidade Gaúcha, Estado do Paraná, com aplicação da equação universal de perdas de solo (EUPS). Acta Sci. Technol., 27:33-42, 2005.

PANACHUKI, E.; ALVES SOBRINHO, T.; VITORINO, A.C.T.; CARVALHO, D.F. \& URCHEI, M.A. Parâmetros físicos do solo e erosão hídrica sob chuva simulada em área de integração agricultura-pecuária. R. Bras. Eng. Agríc. Amb., 10:261-268, 2006.

PANACHUKI, E.; BERTOL, I.; ALVES SOBRINHO, T.; VITORINO, A.C.T.; SOUZA, C.M.A. \& URCHEI, M.A Rugosidade da superfície do solo sob diferentes sistemas de manejo e influenciada por chuva artificial. R. Bras. Ci. Solo, 34:443-441, 2010.

RIBEIRO JÚNIOR, J.I. Análises estatísticas no SAEG. Viçosa, MG, Universidade Federal de Viçosa, 2001. 301p.
ROMERO, N.C.S. Perdas de nutrientes e matéria orgânica por erosão em entre sulcos em Argissolo com resíduos de cana-de-açúcar. Ilha Solteira, Universidade Estadual Paulista Júlio de Mesquita Filho, 2009. 41p. (Tese de Mestrado)

SCHICK, J.; BERTOL, I.; BATISTELA, O. \& BALBINOT JÚNIOR, A.A. Erosão hídrica em Cambissolo húmico alumínico submetido a diferentes sistemas de preparo e cultivo do solo. II - Perdas de nutrientes e carbono orgânico. R. Bras. Ci. Solo, 24:437-447, 2000.

SECCO, D.; REINERT, D.J.; REICHERT, J.M. \& DA ROS, C.O. Produtividade de soja e propriedades físicas de um Latossolo submetido a sistemas de manejo e compactação. R. Bras. Ci. Solo, 28:797-804, 2004.

SOUZA, Z.M.; PAIXÃO, A.C.S.; PRADO, R.M.; CESARIN, L.G. \& SOUZA, S.R. Manejo da palhada de cana colhida sem queima, produtividade do canavial e qualidade do caldo. Ci. Rural, 35:1062-1068, 2005b.

SOUZA, Z.M.; PRADO, R.M.; PAIXÃO, A.C.S. \& CESARIN, L.G. Sistemas de colheita e manejo da palhada de canade-açúcar. Pesq. Agropec. Bras., 40:271-278, 2005 a.

SOUZA, Z.M.; BEUTLER, A.N.; PRADO, R.M. \& BENTO, M.J.C. Efeito de sistemas de colheita de cana-de-açúcar nos atributos físicos de um Latossolo Vermelho. Científica, 34:31-38, 2006.

SHUKLA, M.K.; LAL, R.; OWENS, L.B. \& UNKEFER, P. Land use management impacts on structure and infiltration characteristics of soils in the north Appalachian region of Ohio. Soil Sci., 168:167-177, 2003.

STRECK, C.A.; REINERT, D.J.; REICHERT, J.M. \& KAISER, D.R. Modificações em propriedades físicas com a compactação do solo causada pelo tráfego induzido de um trator em plantio direto. Ci. Rural, 34:755-760, 2004.

THOMPSON, A.L.; GHIDEY, F. \& REDMI, T.P. Raindrop energy effects on chemical and sediment transport. Trans. ASAE, 44:835-841, 2001.

TIM, L.C. Efeito do manejo da palha da cultura da cana-deaçúcar nas propriedades físico-hídricas de um solo. Piracicaba, Escola Superior de Agricultura Luiz de Queiroz, 2002. 127p. (Tese de Doutorado)

WEILL, M.A.M. \& SPAROVEK, G. Estudo da erosão na microbacia do Ceveiro (Piracicaba, SP). II Interpretação da tolerância de perda de solo utilizando o método do Índice de Tempo de Vida. R. Bras. Ci. Solo, 32:815-824, 2008 . 
